\title{
Detection of multi-layer and vertically-extended clouds using A-train sensors
}

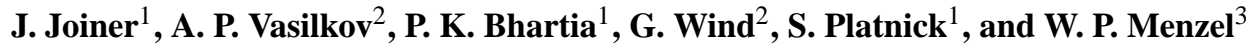 \\ ${ }^{1}$ Goddard Space Flight Center, Laboratory for Atmospheres, Greenbelt, MD, USA \\ ${ }^{2}$ Science Systems and Applications, Inc., 10210 Greenbelt, Rd., Lanham, MD, USA \\ ${ }^{3}$ Cooperative Institute for Meteorological Satellite Studies, Space Science and Engineering Center, University of \\ Wisconsin-Madison, Madison, WI, USA
}

Received: 4 September 2009 - Published in Atmos. Meas. Tech. Discuss.: 28 October 2009

Revised: 29 January 2010 - Accepted: 9 February 2010 - Published: 15 February 2010

\begin{abstract}
The detection of multiple cloud layers using satellite observations is important for retrieval algorithms as well as climate applications. In this paper, we describe a relatively simple algorithm to detect multiple cloud layers and distinguish them from vertically-extended clouds. The algorithm can be applied to coincident passive sensors that derive both cloud-top pressure from the thermal infrared observations and an estimate of solar photon pathlength from UV, visible, or near-IR measurements. Here, we use data from the A-train afternoon constellation of satellites: cloud-top pressure, cloud optical thickness, the multi-layer flag from the Aqua MODerate-resolution Imaging Spectroradiometer (MODIS) and the optical centroid cloud pressure from the Aura Ozone Monitoring Instrument (OMI). For the first time, we use data from the CloudSat radar to evaluate the results of a multi-layer cloud detection scheme. The cloud classification algorithms applied with different passive sensor configurations compare well with each other as well as with data from CloudSat.

We compute monthly mean fractions of pixels containing multi-layer and vertically-extended clouds for January and July 2007 at the OMI spatial resolution $(12 \mathrm{~km} \times 24 \mathrm{~km}$ at nadir) and at the $5 \mathrm{~km} \times 5 \mathrm{~km}$ MODIS resolution used for infrared cloud retrievals. There are seasonal variations in the spatial distribution of the different cloud types. The fraction of cloudy pixels containing distinct multi-layer cloud is a strong function of the pixel size. Globally averaged, these fractions are approximately $20 \%$ and $10 \%$ for OMI and MODIS, respectively. These fractions may be significantly
\end{abstract}

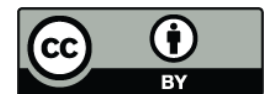

Correspondence to: J. Joiner (joanna.joiner@nasa.gov) higher or lower depending upon location. There is a much smaller resolution dependence for fractions of pixels containing vertically-extended clouds ( $\sim 20 \%$ for OMI and slightly less for MODIS globally), suggesting larger spatial scales for these clouds. We also find higher fractions of verticallyextended clouds over land as compared with ocean, particularly in the tropics and summer hemisphere.

\section{Introduction}

Knowledge of cloud vertical structure, including the presence of multiple cloud layers, is important for a variety of climate-related applications. For example, the knowledge of cloud vertical extents is critical for understanding how clouds impact the Earth's radiation budget (e.g., Gupta et al., 1992; Wielicki et al., 1995) and the vertical distribution of latent heat release that affects global circulation and precipitation (e.g., Wang and Rossow, 1998). By ignoring multiple layering of clouds, one can introduce errors in deducing the radiative impact of clouds (e.g., Chen et al., 2000; Heidinger and Pavolonis, 2005).

The detection of overlapping clouds is critical for quality control of satellite cloud classification schemes and cloud property retrievals that assume a single cloud type within a given field-of-view (e.g., Huang et al., 2006; Wind et al., 2010) such as those described in Rossow and Schiffer (1991) and Platnick et al. (2003). In multi-layer cloud situations, cloud-top pressures derived with the $\mathrm{CO}_{2}$ slicing method may also retrieve an incorrect pressure when the upper layer is semi-transparent (Baum and Wielicki, 1994; Menzel et al., 2008).

Published by Copernicus Publications on behalf of the European Geosciences Union. 
Detection of multiple cloud layers is also important for trace-gas retrievals derived from near-infrared (near-IR) to ultra-violet (UV) solar backscatter measurements. These retrievals are typically implemented with the assumption of a single cloud layer (Ahmad et al., 2004) and using the concept of an optical centroid cloud pressure (OCCP) (see e.g., Koelemeijer et al., 1999; Vasilkov et al., 2004; Sneep et al., 2008, and references therein). The OCCP is more appropriate than the cloud-top pressure for estimation of solar absorption and scattering by well-mixed tropospheric trace gases and is therefore used in many trace-gas retrieval algorithms (e.g., Koelemeijer et al., 1999; Sneep et al., 2008; Ziemke et al., 2009). OCCPs have also been used to compute the effect of various gases on the Earth's short-wave radiation budget (Joiner et al., 2009; Vasilkov et al., 2009).

It has been shown that the solar absorption and scattering are sensitive to the cloud top height and geometrical thickness as well as the cloud optical thickness and fraction (e.g., Kokhanovsky and Rozanov, 2005; Daniel et al., 2003). For vertically-uniform clouds (that do not commonly occur in nature), the OCCP should be placed somewhat inside the cloud, in the vicinity of the geometrical cloud center (e.g., Koelemeijer et al., 2001; de Beek et al., 2001; Sneep et al., 2008; Vasilkov et al., 2008).

Ziemke et al. (2009) showed that tropical deep convective clouds typically have a peak in optical extinction $100 \mathrm{hPa}$ or more inside the cloud, systematically deeper inside clouds that have lower values of total optical thickness. Vasilkov et al. (2008) and Ziemke et al. (2009) further showed that the retrieved OCCP for these clouds tends to be found near the peak in optical extinction. Radiative transfer simulations using cloud optical extinction profiles derived from the CloudSat Cloud Profiling Radar (CPR) and MODerateResolution Imaging Spectroradiometer (MODIS) radiances show that the concept of the OCCP works well in optically thick clouds for retrievals of relatively well-mixed gases such as ozone (Ziemke et al., 2009) in spectral regions where pressure broadening of absorption features is not significant (e.g., UV).

Multiple cloud layers can produce a photon trapping effect between the layers that enhances absorption when the upper cloud deck is not optically thick (optical thickness $\tau<\sim 20$ ) (e.g., Min et al., 2001; Rozanov and Kokhanovsky, 2004; Rozanov et al., 2004; Vasilkov et al., 2008). In such cases, the retrieved OCCP is at an altitude beneath the top of the lower cloud deck. For example, if cirrus is present above low-level clouds (residing at the top of the boundary layer), the retrieved OCCP may be inside the boundary layer. Though this will account for absorption by well-mixed gases with good accuracy (Ziemke et al., 2009), it leads one to incorrectly conclude that there is sensitivity to constituents in the boundary layer. It follows from e.g., Rozanov et al. (2004) that in the presence of multiple cloud decks, significant retrieval errors may occur if the OCCP concept is applied when the distribution of the retrieved trace-gas is vertically-inhomogeneous. This is the case for several pollutants that can be measured with UV/Vis sensors including $\mathrm{NO}_{2}, \mathrm{SO}_{2}, \mathrm{HCHO}$, and absorbing aerosol.

A number of methods have been employed to detect overlapping clouds with passive satellite instruments that offer good spatial coverage. These include

1. The use of a high-spatial resolution imager (the Advanced Very High Resolution Radiometer, AVHRR) to detect the presence of multiple cloud layers within the larger pixel of a coincident sounder (the Highresolution Infrared Radiometer Sounder, HIRS) (Baum et al., 1995)

2. The use of different channel combinations with a $\mathrm{CO}_{2}$ slicing approach (Jin and Rossow, 1997) as applied to HIRS to detect a thin cloud layer $(\tau<1)$ over a lower cloud layer (600-900 hPa with at least $100 \mathrm{hPa}$ separation)

3. A bispectral $(1.63 \mu \mathrm{m}, 11 \mu \mathrm{m})$ approach to similarly detect optically thin high clouds over a lower-level cloud (Baum and Spinhirne, 2000) with enhancements applied to MODIS (Nasiri and Baum, 2004)

4. A multi-spectral (visible and thermal infrared) approach to detect cirrus $(0.5<\tau<4)$ over a lower level cloud $(\tau>5)$ as applied to AVHRR and also applicable to MODIS (Pavolonis and Heidinger, 2004; Heidinger and Pavolonis, 2005).

5. The use of water vapor absorption in the $0.94 \mu \mathrm{m}$ band to infer information about the visible light path as implemented for the MODIS multi-layer flag (Wind et al., 2010).

Other research has focused on the retrieval of cloud properties in two layer cloud systems. For example, Chang and Li (2005a,b) used the MODIS thermal infrared (IR) window channel combined with visible observations to determine optical depths in two layer cloud systems. González et al. (2002) made use of multi-angle observations from the Along-Track Scanning Radiometer (ATSR) to retrieve cirrus cloud properties when lower level clouds are present in the field-of-view. The combination of thermal IR, visible, and microwave data has been used to estimate liquid and ice water paths and other properties in multi-layered clouds (e.g., Sheu et al., 1997; Ho et al., 2003; Huang et al., 2005, 2006; Minnis et al., 2007).

The $94 \mathrm{GHz}$ Cloud Profiling Radar (CPR) on CloudSat (Stephens et al., 2008) has for the first time provided detailed global information about vertical structure of clouds with moderate to high layer optical thicknesses. Due to its nadir-only view and relatively small field-of-view, its daily coverage is limited. However, it can be used to evaluate results from passive sensors that have swath coverage. Because most of the above-mentioned papers were published prior to the launch of CloudSat and the Cloud-Aerosol Lidar and Infrared Pathfinder Satellite Observations (CALIPSO) (Winker 
et al., 2007), only a limited amount of ground- and aircraftbased data was available for evaluation in those works.

In this paper, we focus on identifying multi-layer and vertically-extended clouds that are important for accurate trace-gas retrievals and short-wave radiative transfer calculations. Our approach makes use of two complementary types of observations: thermal IR radiances and photonpath-sensitive solar backscattered measurements. We use two different expressions of the solar photon path; One is provided by UV rotational-Raman scattering (RRS) (Joiner et al., 1995) in the form of the OCCP (Vasilkov et al., 2008) and the other is the MODIS multi-layer flag (MLF). The OCCP is derived with the Dutch/Finnish Ozone Monitoring Instrument (OMI) (Levelt et al., 2006) flying aboard the National Aeronautics and Space Administration (NASA) Earth Observing System (EOS) Aura satellite. We also use the cloud-top pressure and total cloud optical thickness derived with the EOS Aqua MODIS (Platnick et al., 2003). We qualitatively and quantitatively evaluate the approach for a wide range of conditions using the CloudSat CPR cloud mask and CloudSat/MODIS-derived optical depth profile retrievals. This is the first time, to our knowledge, that such comparisons have been made. All of these satellites are part of the "A-train" constellation in polar orbits that cross the equator near 13:30 LT.

The approach developed here could be applied generally to any satellite or constellation that contains both thermal IR and solar backscatter cloud pressure measurements. The latter techniques include the use of $\mathrm{O}_{2}-\mathrm{O}_{2}$ bands (e.g., Sneep et al., 2008) and the $\mathrm{O}_{2}$ A-band (e.g., Rozanov et al., 2004; Vanbauce et al., 2003). Such measurements are made from instruments on current and future meteorological satellites such as MetOp, the National Polar Orbiting Environmental Satellite System (NPOESS), and the NPOESS Preparatory Project (NPP). However, these satellites will not have the high-spatial resolution (imaging) for multi-layer cloud detection that is afforded by the MODIS MLF. An advantage of our approach is that the combination of photon pathlengthsensitive UV/VIS observations with thermal IR for multilayer cloud detection can be applied over ocean and most land surfaces. Microwave observations, in contrast, have more limited sensitivity to cloud liquid water over land.

The paper is organized as follows: Sect. 2 describes the observations used here. The algorithms and sample results are presented in Sect. 3. Section 4 shows the evaluation of the cloud classification results with CloudSat. Monthly mean maps and statistics for two months are provided in Sect. 5. Conclusions are given in Sect. 6.

\section{Observations}

We use the following quantities that are provided in Atrain level 2 (L2) cloud data sets for our cloud classification scheme:
1. Cloud-top pressure $\left(P_{\text {top }}\right)$ retrieved with MODIS thermal IR channels by the $\mathrm{CO}_{2}$ slicing approach (Menzel et al., 2008) for high clouds or with the window channel brightness temperature for lower clouds at $(5 \mathrm{~km})^{2}$ resolution

2. Cloud optical thickness $(\tau)$ derived from MODIS visible observations (Platnick et al., 2003) at $(1 \mathrm{~km})^{2}$ native resolution

3. Optical centroid cloud pressure (OCCP) from the OMI rotational-Raman (OMCLDRR) algorithm (Joiner et al., 2004; Joiner and Vasilkov, 2006) or the MODIS multilayer flag (MLF) (Wind et al., 2010) at $(1 \mathrm{~km})^{2}$ native resolution

MODIS and OMI data are from collections 5 and 3, respectively.

Menzel et al. (2008) state that a reliable MODIS IR $P_{\text {top }}$ retrieval is possible for integrated optical depths greater than unity, noting that MODIS detects the radiative mean of cirrus clouds in the $\mathrm{CO}_{2}$ bands that is frequently more than $1 \mathrm{~km}$ inside the cloud as determined by lidar measurements.

The MODIS MLF is composed of several tests designed to detect multi-layer clouds that would adversely impact the cloud effective radius retrievals. The main test checks the consistency of above-cloud precipitable water calculated two different ways: 1) The precipitable water from the National Centers for Environmental Prediction (NCEP) $6 \mathrm{hr}$ global analysis is integrated above the cloud-top pressure determined from the thermal IR $\mathrm{CO}_{2}$ slicing method (Menzel et al., 2008) that uses MODIS bands between 13.3 and $14.2 \mu \mathrm{m}$. 2) Above-cloud precipitable water vapor is computed using reflectance differences in the 0.86 and $0.94 \mu \mathrm{m}$ near-IR bands with a table lookup approach (Wind et al., 2010). Because water vapor is the main absorber in the $0.94 \mu \mathrm{m}$ band, differences in reflectance can be attributed to above-cloud water vapor. When the two methods disagree by more than $8 \%$ of the total integrated column water vapor amount, the pixel is flagged as potentially containing multilayered clouds.

The MODIS MLF has values 0-8 with 0 indicating clear sky, 1 indicating a single-layer cloud or that a retrieval was not attempted, and higher numbers indicating greater levels of confidence in detecting multi-layer or multi-phase clouds. Values greater than 2 are considered reliable. A value of 2 is a test on the agreement between two different methods to determine cloud thermodynamic phase. This test tends to lose confidence at high latitudes where one of the phase tests tends to become unreliable and may produce false positive detections. The MODIS MLF is designed primarily to detect cases that are problematic for quality MODIS cloud effective radius retrievals (e.g., liquid water cloud retrievals in the presence of overlying cirrus); It is not designed to detect every instance of multi-layer/multi-phase clouds (Wind et al., 2010). To trigger the MODIS MLF, the combined extinction optical depth must be $>4$. 

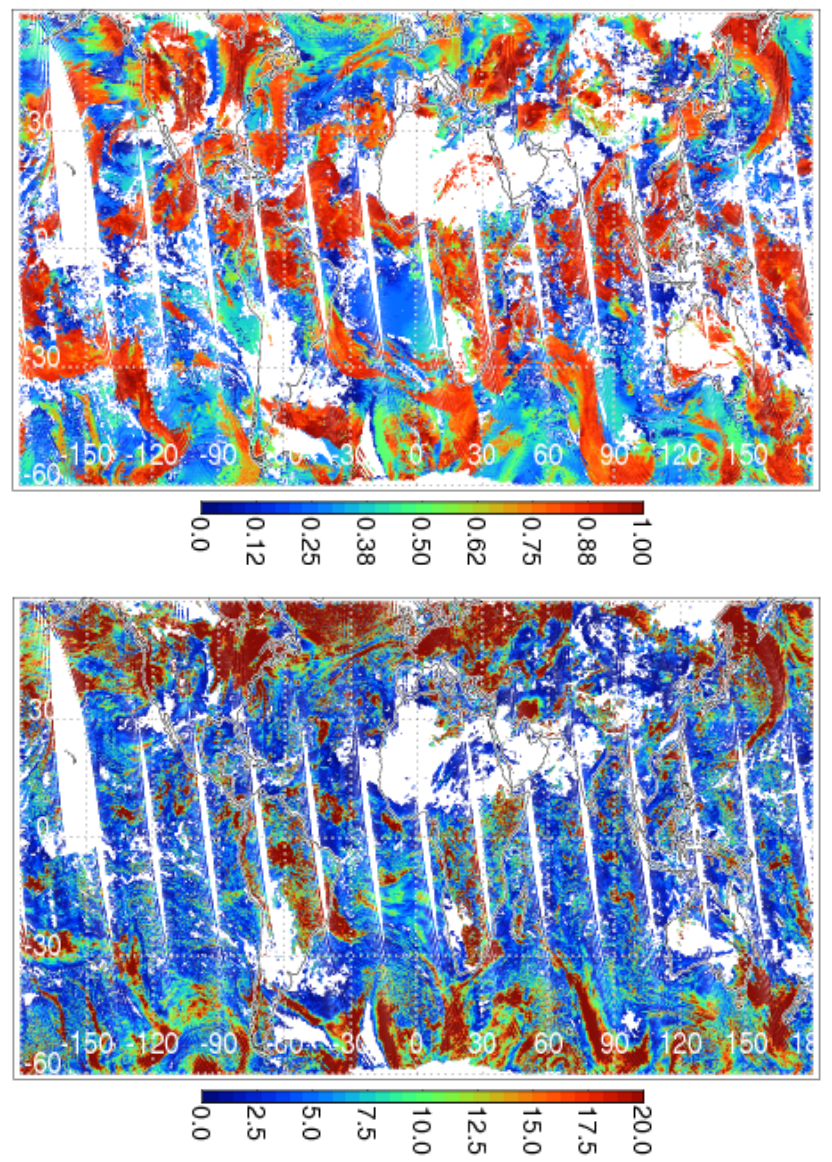

Fig. 1. Mapped cloud data from 13 November 2006; Top: Fractional cloud-top pressure ( $\Delta P_{\text {top }}$, see text); Bottom: MODIS mean cloud optical thickness $(\tau)$ within an OMI footprint. White indicates no data are available, cloud fractions are zero, or snow/ice. Latitudes and longitudes are indicated.

For bright clouds (reflectivities $>80 \%$ ), the OMI Raman OCCP is defined as the pressure at which a Lambertian cloud is placed in order to produce the observed amount of rotational-Raman scattering. In broken and less bright clouds, the OCCP is retrieved within the context of the Mixed-Lambertian Equivalent Reflectivity (MLER) cloud model in which scattering and absorption occurring within and below a thin or broken cloud is accounted for by treating the pixel as if it was composed of clear and cloudy parts, weighted appropriately by the fractions of total radiance contributed by those parts. This model provides values close to the geometrical center of the cloud for uniform clouds at moderate solar and satellite zenith angles. Values can deviate somewhat from this for optically thin clouds, especially at very high and low solar zenith angles (e.g., Vasilkov et al., 2008). We have already discussed some of the effects of vertical inhomogeneity on the OCCP. In addition, the OCCP can also be affected by horizontal cloud inhomogeneity or threedimensional (3-D) effects (e.g., Kokhanovsky et al., 2007; Wagner et al., 2009).
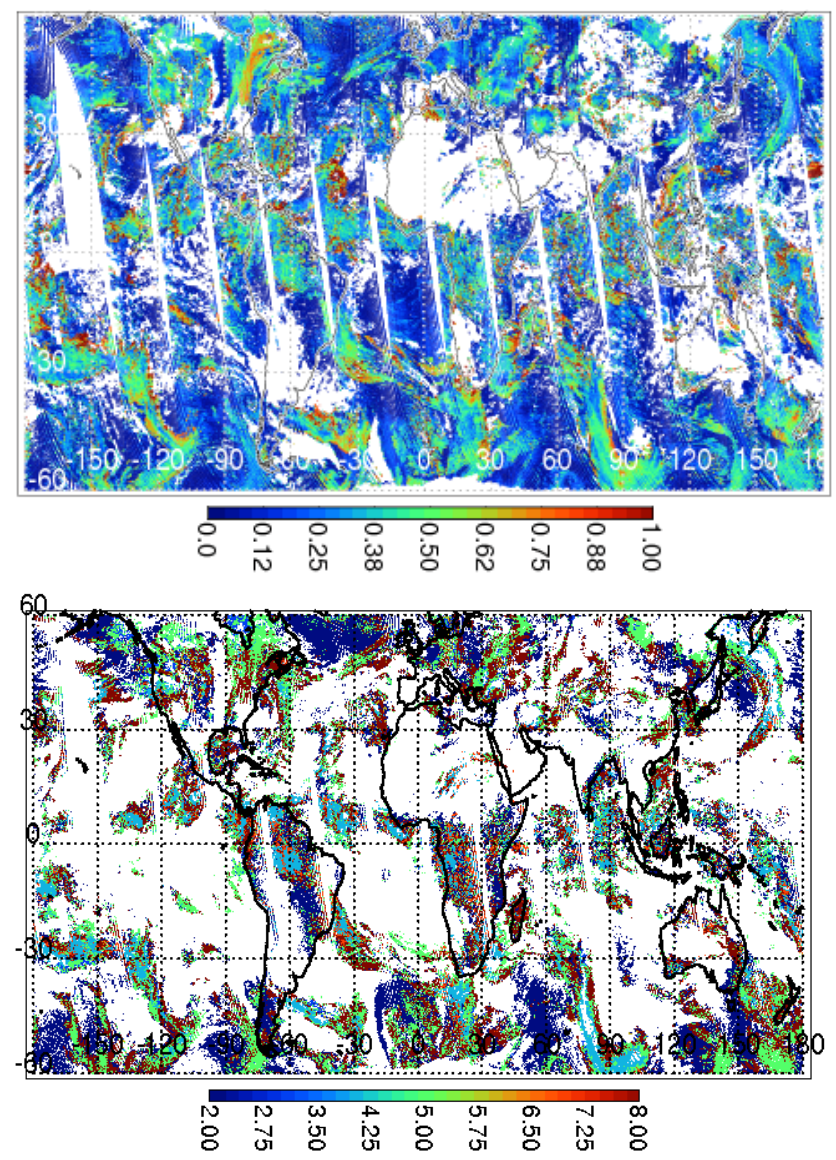

Fig. 2. As in Fig. 1 but showing fractional cloud pressure difference (OMI-MODIS), $\Delta P_{\text {diff }}$ (top) and MODIS maximum multi-layer flag (MLF) value within an OMI footprint (pixels where $M L F \geq 2$, bottom).

Our data analysis is conducted at either the OMI footprint $(\sim 12 \mathrm{~km} \times 24 \mathrm{~km}$ at nadir) or in MODIS standard $5 \mathrm{~km} \times 5 \mathrm{~km}$ blocks used for thermal IR cloud property retrievals. We apply a simple collocation scheme to provide MODIS information at the OMI footprint. For each MODIS level 2 data element, we find the OMI pixel with the smallest chordal distance between OMI and MODIS pixel centers. Statistical information is then generated for the MODIS data on each OMI footprint (mean, standard deviation, minimum, and maximum). The MODIS multi-layer flag is said to be set when the maximum value within either the OMI footprint or the $5 \mathrm{~km} \times 5 \mathrm{~km}$ block is $\geq 2$.

Figures 1 and 2 show a single day of the quantities used in our classification scheme. The cloud top pressure is expressed in terms of a fraction of the tropopause thickness; $\Delta P_{\text {top }}=\left(P_{s}-P_{\text {top }}\right) /\left(P_{s}-P_{\text {trop }}\right)$, where $P_{\text {trop }}$ is a latitudinally-dependent estimate of the tropopause pressure provided in the MODIS data set, and $P_{S}$ is a climatological surface pressure provided in the OMI data set. This representation was chosen such that the variable thickness of the troposphere is taken into account. $\Delta P_{\text {top }}$ approaches 


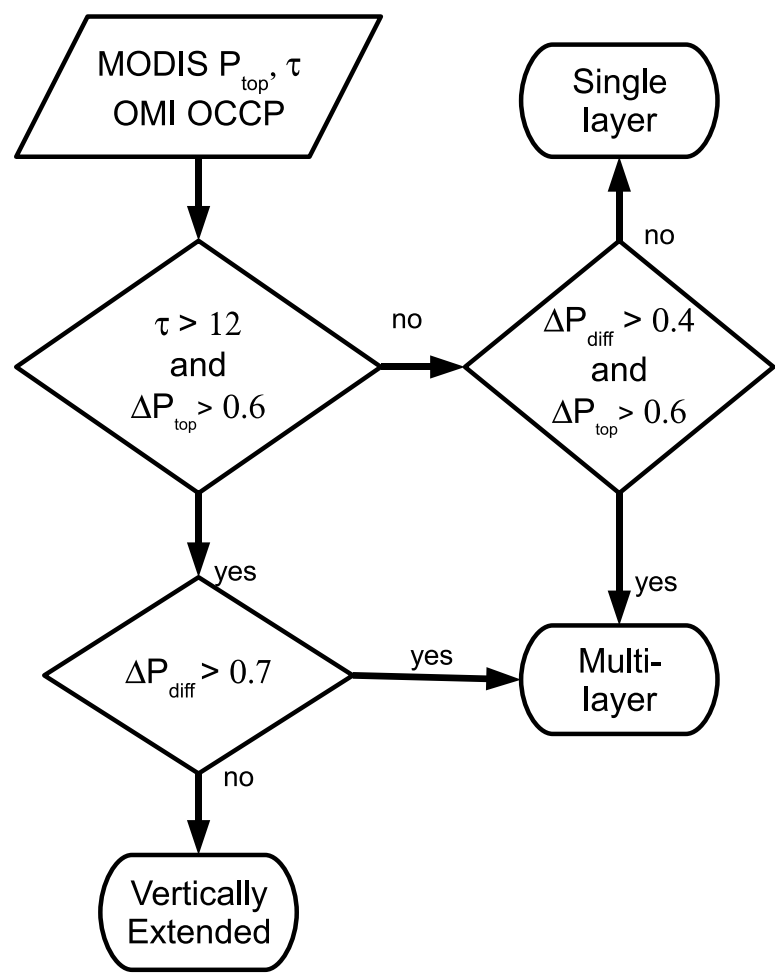

Fig. 3. Flow chart describing OMI/MODIS multi-layer/extended cloud detection scheme.

unity (zero) for cloud tops near the tropopause (surface). The OMI OCCP is differenced from the MODIS cloud-top pressure and also expressed as a fraction of the tropopause thickness; $\Delta P_{\text {diff }}=\left(\mathrm{OCCP}-P_{\text {top }}\right) /\left(P_{s}-P_{\text {trop }}\right)$. In theory, $\Delta P_{\text {diff }}$ should always be positive. When computed from the retrievals, $\Delta P_{\text {diff }}$ is sometimes negative as a result of errors in the derived cloud-top pressure and/or optical centroid pressure. The color scale in Figs. 1 and 2 saturates such that values outside the indicated range are colored as either the high or low end of the color scale. Therefore, negative values of $\Delta P_{\text {diff }}$ appear as zero.

In the tropics, clouds with high optical thicknesses often have cloud tops near the tropopause. However, clouds with high tops do not always have high optical thicknesses. In the high latitude storm track regions, clouds with high optical thicknesses also frequently have high cloud tops; However, many clouds with high optical thickness have cloud tops in the lower to middle troposphere. At the edges of convective cells and fronts, the values of $\Delta P_{\text {diff }}$ can be quite large and the MODIS MLF also shows high confidence levels, strongly suggesting the presence of multi-layer clouds. The MLF is not always set in the centers of these areas where ice optical thicknesses can be quite high. MLF values of 2 (lowest confidence) commonly occur at high latitudes for low clouds with small $\Delta P_{\text {diff. }}$ These are likely false positive detections. However, at lower latitudes there are cases of $M L F=2$ that coincide with high clouds and large values of $\Delta P_{\text {diff. }}$.

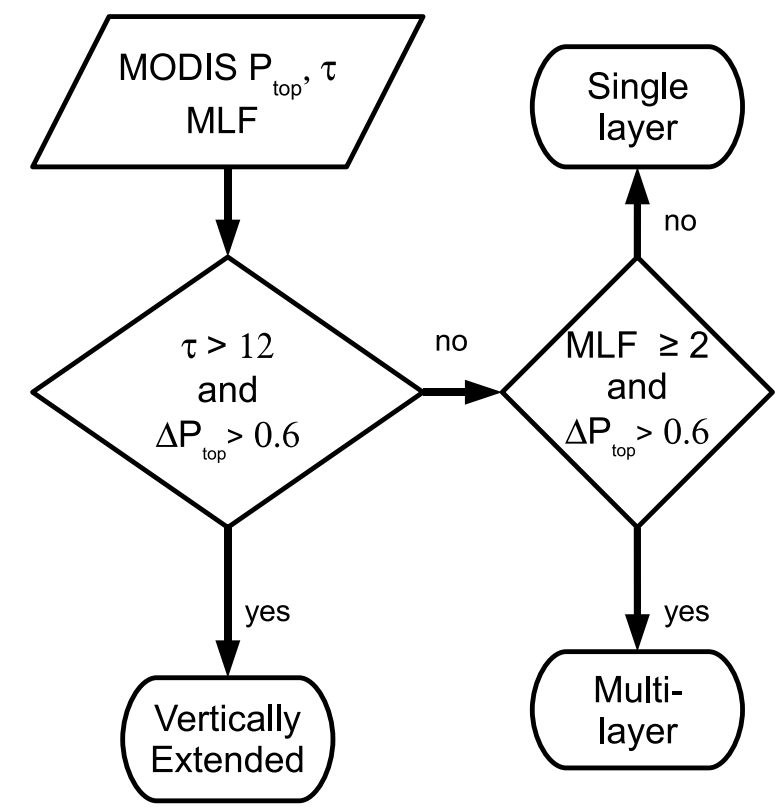

Fig. 4. Flow chart describing MODIS multi-layer/extended cloud detection scheme.

\section{Approach}

We next develop two relatively simple cloud identification schemes using the retrieved $\tau$ and $P_{\text {top }}$ from MODIS along with either the OMI OCCP or the MODIS MLF. Pixels are classified as either single-layer, distinct multi-layer, or vertically-extended (e.g., convective). We focus exclusively on pixels that do not overlie ice or snow surfaces. Here, we attempt to detect multi-layer situations where the top layer resides in the upper troposphere and the lowest layer in the lower troposphere (with a separation of at least $\approx 200 \mathrm{hPa}$ ). The top layer must be optically thick enough $(\tau>\sim 1)$ to be identified in the upper troposphere by the MODIS $\mathrm{CO}_{2}$ slicing algorithm.

The MODIS total cloud optical thickness, $\tau$, is used to help distinguish distinct multi-layer clouds from verticallyextended clouds, defined here as contiguous cloud layers (no more than $50 \mathrm{hPa}$ separation) with extents covering a significant fraction (at least 40\%) of the troposphere. With CloudSat, we find that clouds with high tops and $\tau \geq 12$ are almost always vertically-extended. When $\tau<12$, the cloud top pressure and either the MLF or the OMI OCCP (in the form of $\left.\Delta P_{\text {diff }}\right)$ are used to distinguish single from multi-layer clouds.

Figures 3-4 show flow charts for the OMI/MODIS combination (using the OMI OCCP) and the MODIS-only scheme (using the MODIS MLF), respectively. The latter can be applied at either the OMI or MODIS resolution. Note that the MODIS MLF value refers here to the maximum value at the resolution considered. The OMI/MODIS algorithm contains an extra check not found in the MODIS-only algorithm that 


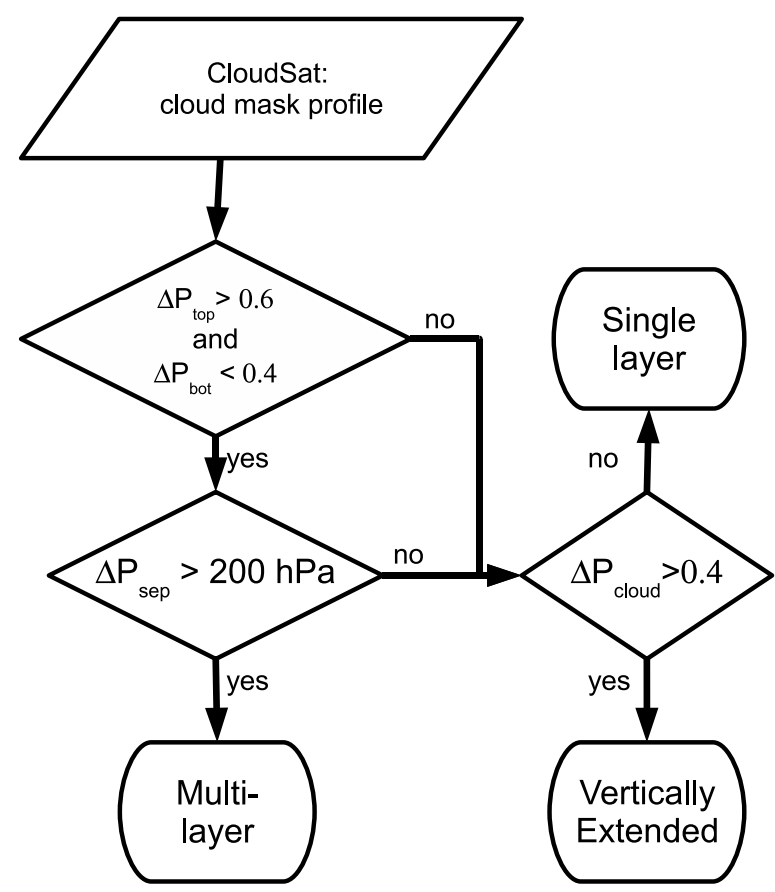

Fig. 5. Flow chart describing CloudSat multi-layer/extended cloud detection scheme.

identifies very infrequent situations $(<1 \%)$ of distinct multiple cloud layers with $\tau \geq 12$ and a high cloud top.

We determined threshold values empirically using CloudSat data. We find that minor adjustments about these threshold values do not significantly change the results. For example, the agreement with CloudSat shown in the next section changes by less than $2 \%$ when the $\tau$ threshold is varied from 8 to 16. Similar results are obtained when the $\Delta P_{\text {top }}$ threshold is varied from $0.5-0.7$. The agreement changes by less than $1 \%$ when the $\Delta P_{\text {diff }}$ threshold is varied from $0.3-0.5$.

For the threshold value of the MLF in the MODIS-only algorithm, we tested values of both MLF $>2$ and $\geq 2$. Although MLF values of $\geq 2$ appear to produce false positive detections of multi-layer clouds at high latitudes, when used in conjunction with the high cloud and vertically-extended tests, most of the false positives are removed and better agreement with the OMI-MODIS results is obtained at low and middle latitides. The agreement with CloudSat on the OMI footprint is slightly improved (by $\leq 1 \%$ ). We therefore use the threshold of $M L F \geq 2$.

A similar algorithm is applied to CloudSat at either the along-track resolution of OMI $(12 \mathrm{~km})$ or MODIS $(5 \mathrm{~km})$. Figure 5 shows a flow chart of the CloudSat scheme. There is no dependence on $\tau$ as there is for the passive sensors. Clouds are said to be present in a layer $l$ when the CloudSat mask shows a reliable detection in that layer (value $>5$ ). $\Delta P_{\text {top,CS }}$ and $\Delta P_{\text {base,CS }}$ are defined similarly to the passive sensors but using the cloud top and base from CloudSat. $\Delta P_{\text {cloud }}=\left(P_{\text {bottom, highest }}-P_{\text {top, highest }}\right) /\left(P_{s}-P_{\text {trop }}\right)$ is the
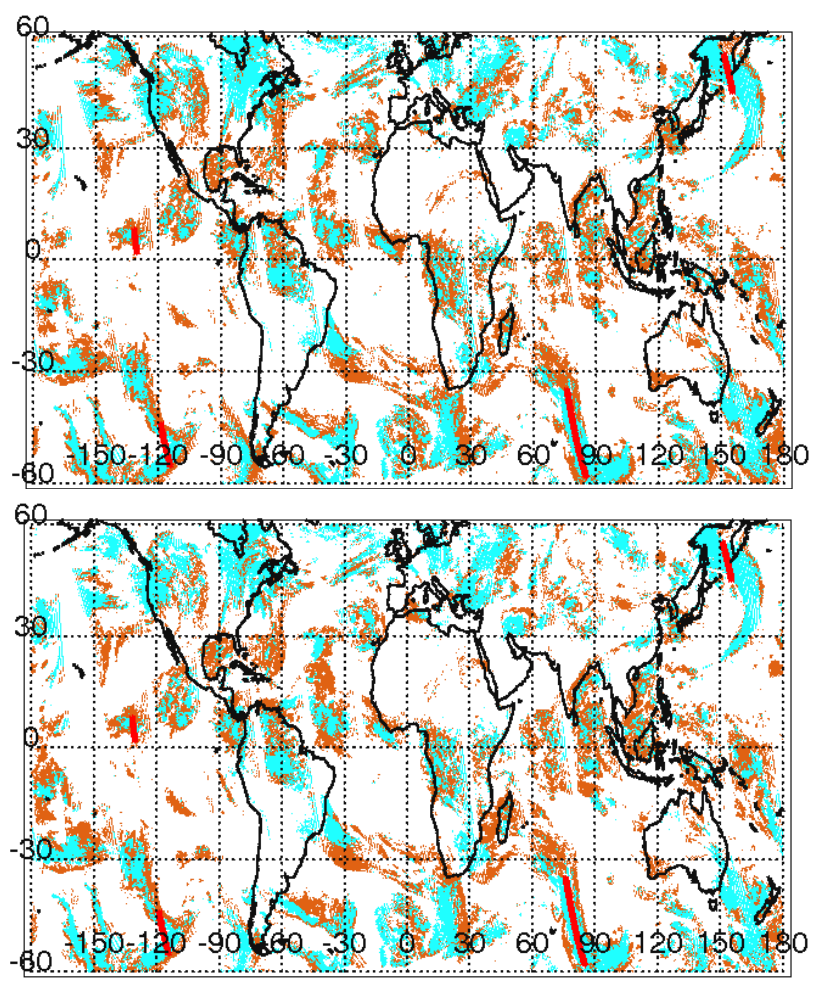

Fig. 6. Results of multi-layer detection for 13 November 2006. Top: MODIS-only (on the OMI footprint); Bottom: OMI/MODIS; Light blue: Vertically-extended; Orange: Distinct multi-layer; Red thick lines: Selected CloudSat orbital tracks.

ratio of the geometrical thickness of the highest cloud deck to the tropopause thickness. $\Delta P_{\text {sep }}$ is the largest separation $(>50 \mathrm{hPa}$ ) between cloud layers. We check all layers with pressures $>150 \mathrm{hPa}$ and at least $50 \mathrm{hPa}$ less the surface.

It is important to note that CloudSat has a very narrow field-of-view $(\sim 1.4 \mathrm{~km})$ as compared with the cross-track size of an OMI pixel (minimum of $24 \mathrm{~km}$ ). Therefore, the clouds viewed in the thin CloudSat slice through an OMI pixel may not be representative of the situation within the larger OMI pixel when there is significant spatial inhomogeneity. We must then detect these situations and eliminate them from the sample space used in our comparison. The details of our filtering scheme are described in Appendix A.

\section{Results}

\subsection{Passive sensor single day classification}

Figure 6 provides results of the passive-sensor cloud classification schemes on the OMI footprint for the same date shown in Fig. 1. Data are plotted only where either extended or distinct multi-layer clouds are detected. For all other cloudy pixels (as indicated in the cloud optical thickness shown in Fig. 1), the algorithms classified clouds as single layer. In general, both algorithms produce similar results. This 
shows that once the vertically-extended clouds have been removed, the MODIS MLF provides information that is similar to the difference between the cloud-top and the OCCP, provided that the cloud top is in the upper troposphere. The OMI/MODIS combination tends to find somewhat more distinct multi-layer clouds at lower latitudes, while the opposite is true at high latitudes as will be discussed in more detail below.

$\Delta P_{\text {diff }}$, as shown in Fig. 2, can be considered as a measure of confidence for the OMI/MODIS scheme as larger values are likely to occur where there are distinct cloud layers. CloudSat orbital tracks are shown for areas that will be examined in more detail below.

\subsection{Global comparison of passive- and active-sensor classifications}

We quantitatively compare passive and active cloud classifications using the confusion matrix concept. Table 1 shows comparisons for the three different passive sensor configurations (MODIS/OMI algorithm and MODIS-only algorithm applied at both the OMI and MODIS resolutions) for collocations occurring on 13 November 2006. The top left element of each $2 \times 2$ matrix (first two lines under each instrument configuration) gives the fraction of cases (in \%) when both passive and active sensors identify single layer clouds. Similarly, the bottom right elements show the percentage of samples where either multi-layer or extended clouds are identified by both active and passive sensors. The trace (third line under each configuration) is the percentage of all samples where both types of sensors agree. The off-diagonal elements represent the different types of error. If we consider CloudSat to be truth and our goal to detect multi-layer/extended clouds, then a type I error would be defined as a missed multilayer/extended cloud, i.e., the upper right element. Type II errors (lower left element) are false detections of multi-layer and extended clouds.

With our filtering scheme, the sample sizes are 4602 and 15421 at the OMI and MODIS spatial resolutions, respectively. This represents approximately $64 \%$ (74\%) of the total number of cloudy samples for the OMI (MODIS) resolutions. The percentage of correct identifications was similar (nearly $85-90 \%$ ) for all cases, while the partitioning of the different types of error varied somewhat depending upon the instrument configuration and spatial resolution.

Next we examine how well the algorithms further distinguish between vertically-extended and distinct multi-layer clouds. Table 2 provides the results in the form of similar $3 \times 3$ matrices. Agreement is obtained in $\approx 80 \%$ of the pixels for all three configurations, indicating that our algorithms are effective in identifying cases of distinct multiple layers and separating these from vertically-extended clouds. MODIS results at the MODIS resolution are somewhat poorer than those obtained on the OMI footprint. The increased errors at the smaller footprint mainly stem from false detection of
Table 1. Cloud classification statistics (single or multilayer/vertically-extended) for passive sensor versus CloudSat (\%).

\begin{tabular}{cccc}
\hline Passive sensor configuration & $\begin{array}{c}\text { CloudSat } \\
\text { single } \\
\text { layer }\end{array}$ & $\begin{array}{c}\text { CloudSat } \\
\text { multi+ } \\
\text { extended }\end{array}$ & $\begin{array}{c}\text { Total in } \\
\text { agreement }\end{array}$ \\
\hline
\end{tabular}

\section{MODIS/OMI on OMI footprint}

$\begin{array}{lrr}\text { MODIS/OMI single layer } & 48.7 & 10.8 \\ \text { MODIS/OMI multi+extended } & 2.0 & 38.6 \\ \text { Total in agreement } & & \end{array}$

\section{MODIS-only on OMI footprint}

$\begin{array}{lcr}\text { MODIS-only, single layer } & 47.0 & 5.3 \\ \text { MODIS-only, multi+thick } & 3.7 & 44.0\end{array}$

Total in agreement

5.3

MODIS-only at $5 \mathrm{~km} \times 5 \mathrm{~km}$

$\begin{array}{lrr}\text { MODIS-only, single layer } & 53.3 & 6.8 \\ \text { MODIS-only, multi+thick } & 9.8 & 30.1 \\ \text { Total in agreement } & & \end{array}$

91.0

multi-layer clouds. This likely results in part from the fact that the filtering scheme for the MODIS resolution data only includes a single check on the cloud top pressure. If we apply the same filtering scheme to the MODIS-only results at the OMI resolution, the number of samples increases significantly and the agreement with CloudSat degrades to values similar to those obtained at the MODIS resolution.

Here, we have focused on multi-layer situations where both MODIS and CloudSat see high clouds. This will generally be the case for high clouds with $\tau>1$. MODIS may not correctly place the cloud top for high clouds with $\tau<1$. CloudSat may also not see these high thin clouds. For the trace-gas retrievals mentioned above, these optically thin clouds will have a negligible impact; The photon-trapping effect will be very small (Vasilkov et al., 2008) in these situations and thus the centroid pressure of a lower layer should be accurately retrieved. However, the MODIS effective radii retrievals may still be negatively impacted by undetected multilayer clouds with an optically thin upper layer.

As with any threshold algorithm (and when comparing results from different threshold algorithms), we expect some fraction of errors to occur when threshold values are approached. In this particular comparison, we also expect errors to occur as a result of scene inhomogeneity and errors in our assessment of whether CloudSat's view is representative of the results in a larger pixel. Results improve when we place tighter restrictions on our filtering scheme. However, this results significantly smaller sample sizes and a degraded ability to assess the results visually as in the case studies shown in Sect. 4.3. The accuracies obtained in this study should be adequate for most applications related to trace-gas retrievals. However, greater accuracy may be required for applications not discussed or envisaged here. 
Table 2. Cloud classification statistics (single layer, distinct multi-layer, and vertically-extended) for passive sensor versus CloudSat (\%).

\begin{tabular}{lcccc}
\hline Passive sensor configuration & $\begin{array}{c}\text { CloudSat } \\
\text { single layer }\end{array}$ & $\begin{array}{c}\text { CloudSat } \\
\text { extended }\end{array}$ & $\begin{array}{c}\text { CloudSat } \\
\text { multi-layer }\end{array}$ & $\begin{array}{c}\text { Total in } \\
\text { agreement }\end{array}$ \\
\hline MODIS/OMI on OMI footprint & & & & \\
MODIS/OMI single layer & 48.7 & 3.9 & 6.9 & \\
MODIS/OMI extended & 1.7 & 19.1 & 5.8 & \\
MODIS/OMI multi-layer & 0.3 & 2.5 & 11.3 & 79.0 \\
Total in agreement & & & & \\
MODIS-only on OMI footprint & & & & \\
MODIS-only, single & 47.0 & 1.9 & 3.4 & \\
MODIS-only, extended & 1.7 & 19.1 & 6.0 & \\
MODIS-only, multi-layer & 2.0 & 4.4 & 14.5 & \\
Total in agreement & & & & \\
MODIS-only at 5 km $\times \mathbf{5}$ km & & & & \\
MODIS-only, single layer & 53.3 & 3.2 & 3.6 & \\
MODIS-only, extended & 2.7 & 17.8 & 2.8 & \\
MODIS-only, multi-layer & 7.1 & 4.2 & 5.3 & \multirow{2}{*}{76.4} \\
Total in agreement & & & & \\
\hline
\end{tabular}

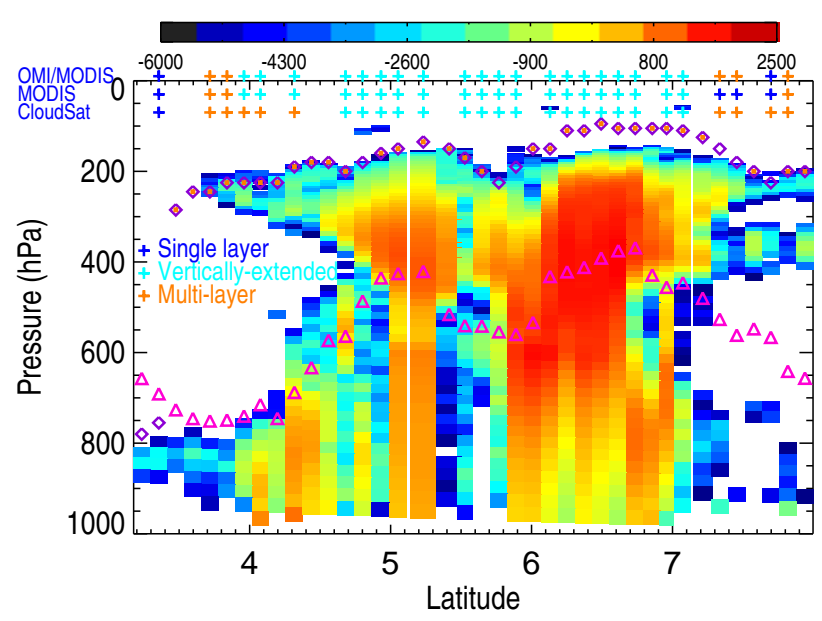

Fig. 7. CloudSat radar reflectivities (arbitrary units) along OMI orbit 12402 (western track in tropical Pacific highlighted in Fig. 6); Averaged along-track over OMI pixel $(\sim 13 \mathrm{~km})$; Pink triangles: OMI optical centroid cloud pressure; Purple diamonds: MODIS minimum cloud-top pressure within closest passive sensor footprint, orange-filled where MODIS maximum multi-layer flag $>2$. Colored '+' symbols at the top are the results of the cloud classification algorithms described in Figs. 3-5. Results are shown only for pixels passing the filtering scheme described in the Appendix.

\subsection{Case studies}

We next present several case studies to qualitatively evaluate our filtering scheme and results. Figures 7 and 8 show CloudSat radar reflectivities along orbital tracks shown in Fig. 6 at OMI and MODIS resolutions, respectively. The results of our cloud classification algorithms for the passive

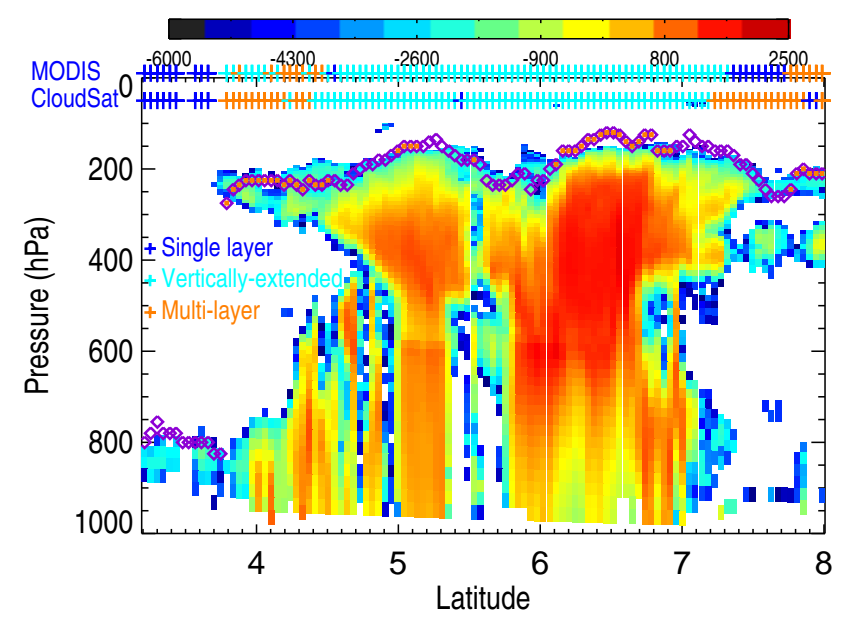

Fig. 8. Similar to Fig. 7 but averaged along-track over the MODIS $5 \mathrm{~km}$ resolution. Cloud-top pressures are those from the closest MODIS $(5 \mathrm{~km})^{2}$ block.

sensors and CloudSat are shown across the top of these figures only for pixels that passed our representative tests. We note several instances where our filtering scheme has removed obvious cases where CloudSat was not representative of the conditions observed within the OMI or MODIS pixels. For example, near $3.5^{\circ}$ latitude, high clouds are detected by MODIS within the OMI pixel and are not seen in the CloudSat slice. Since these high cirrus are contiguous along the track, this is unlikely to be a MODIS error. Likewise, the low clouds near $3^{\circ}$ appear to be scattered and not always seen in the CloudSat curtain. Near $7.5^{\circ}$, the low clouds are likely scattered and not always seen by CloudSat. 


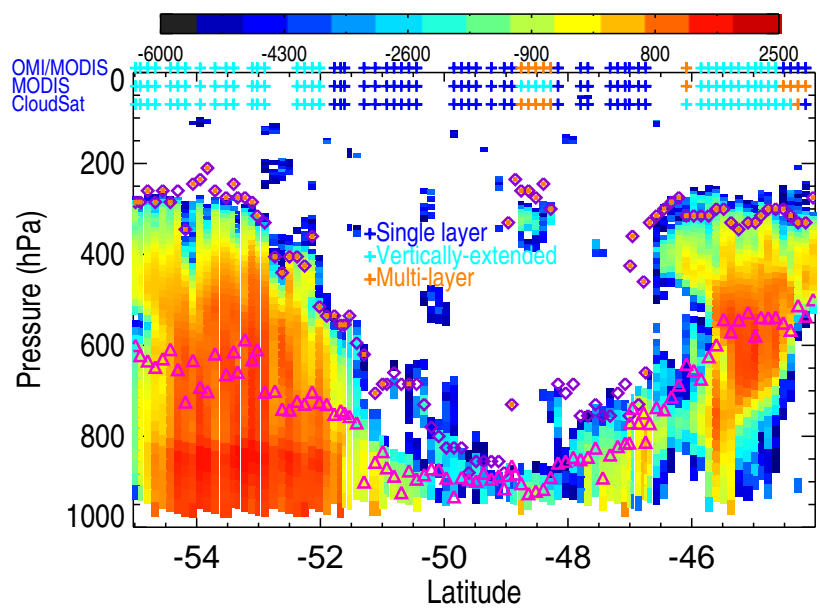

Fig. 9. As in Fig. 7 but for the southern high latitude storm track along OMI orbit 12402 (western and southernmost track highlighted in Fig. 6).

The OMI/MODIS and MODIS-only algorithms produce similar results and good agreement with CloudSat. There are many cases of positive identification of multi-layer clouds by both algorithms. Figure 7 shows that there are a few cases where OMI/MODIS identifies clouds as extended, but CloudSat shows distinct multi-layered clouds. If we apply a more stringent filter (using sub-pixel variation in the MODIS IR brightness temperature), some of these are eliminated.

The MODIS-only algorithm misses some of the multilayer clouds between 7 and $8^{\circ} \mathrm{N}$ which is shown more clearly in Fig. 8 at the MODIS along-track resolution. Either the lower cloud deck may not have had a sufficient mean optical thickness or the upper deck may have been too optically thick to trigger the MODIS MLF in these pixels. The OMI OCCP only hints at the presence of a lower cloud deck there. The MODIS multi-layer flag performs well in detecting distinct multiple layer cases, but behaves somewhat unpredictably in the vertically-extended clouds.

Figure 9 shows results at high southern latitudes for variety of different cloud conditions. Because our threshold tests are few, simplistic, and based upon CloudSat data, it is not surprising to see good agreement between the passive sensor algorithms and CloudSat. The multi-layer situation near $49^{\circ} \mathrm{S}$ shows an example of the relatively infrequent scenario where the total optical thickness in the OMI pixels was $>12$, but the clouds were distinctly multi-layer. The extra path in the OMI/MODIS flow chart allows these multi-layer situations to be correctly identified, while the MODIS-only algorithm incorrectly identifies them as vertically-extended. However, at the MODIS spatial resolution (not shown), the mean optical depths for those collocated pixels were $<12$ so that the clouds were correctly identified as distinct multi-layer when the optical depth of the upper cloud layer was high enough for the high clouds to be detected. This suggests that
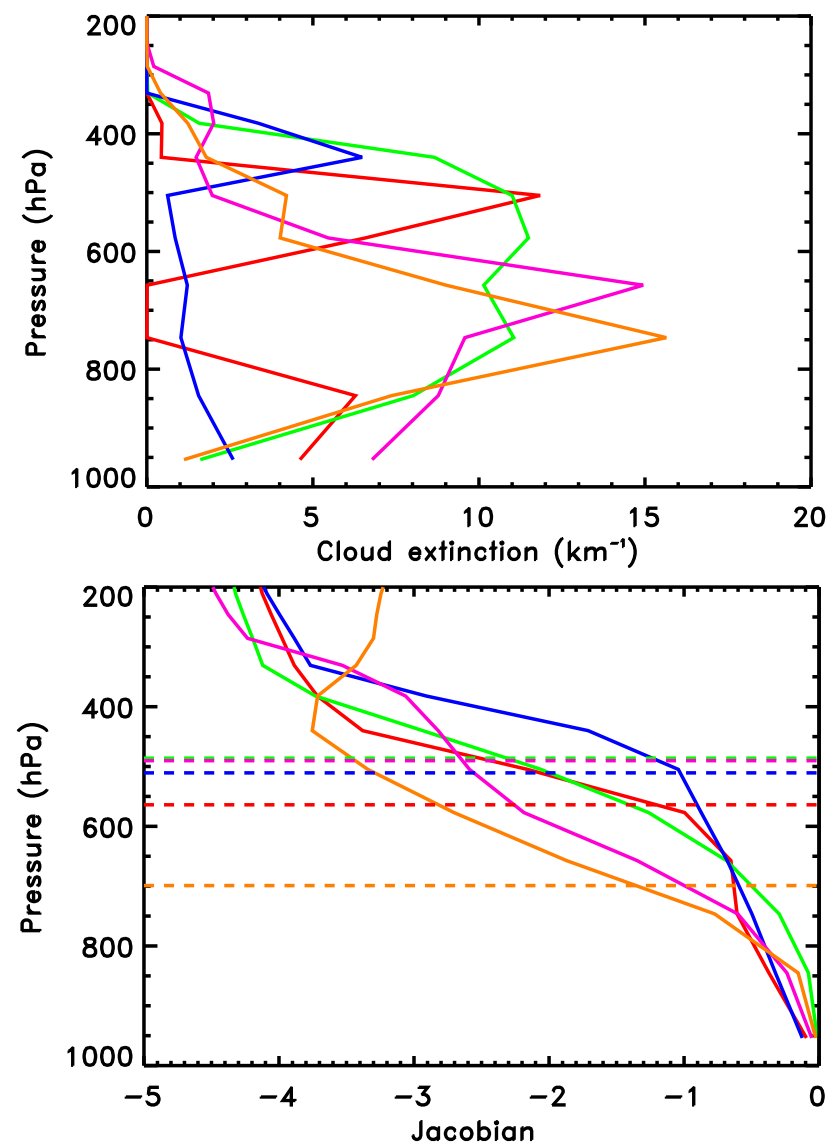

Fig. 10. Top: CloudSat/MODIS cloud extinction for cases described in Table 3; Bottom, solid lines: corresponding ozone Jacobian, $\partial \ln (I) / \partial \tau_{l}\left(\mathrm{O}_{3}\right)$; dashed lines: OMI retrieved optical centroid cloud pressures (OCCPs).

optically-thicker clouds, perhaps vertically extended, were present within the OMI pixel, but our CloudSat filtering scheme was unable to identify the pixels as unrepresentative.

To gain some insight into the behavior of the OCCP, we examine several individual cloud extinction profiles from the CloudSat 2B-Tau product in the two eastern-most high latitude CloudSat tracks in Fig. 6. This product is derived using a combination of CloudSat radar reflectivities and MODIS radiances. We compute the corresponding ozone Jacobian assuming a uniformly mixed ozone profile in the troposphere using the radiative transfer model of Spurr et al. (2008). Figure 10 shows the results for 5 different profiles detailed in Table 3. The Jacobian is defined here as the change in the natural log of the radiance with respect to the layer ozone optical depth (equally spaced layers in altitude).

The least amount of photon penetration occurs for the profile with a sharp peak in extinction near $450 \mathrm{hPa}$ (blue) with lower amounts of extinction below. The greatest amount of photon penetration occurs for the profile with a large extinction peak near $750 \mathrm{hPa}$ (orange). In between is a profile with 
Table 3. Information corresponding to cloud extinction profiles shown in Fig. 10. MODIS $\tau$ is the MODIS 1 km retrieved $\tau$ averaged over the OMI footprint; CloudSat $\tau$ is the 2B-Tau averaged over the along-track extent of the OMI pixel; CTP is the MODIS minimum cloud-top pressure within the OMI footprint.

\begin{tabular}{lrcccccccc}
\hline $\begin{array}{l}\text { Orbit } \\
\text { OMI }\end{array}$ & Lat. & Long. & $\begin{array}{c}\tau \\
\text { MODIS }\end{array}$ & $\begin{array}{c}\tau \\
\text { CloudSat }\end{array}$ & $\begin{array}{c}\text { CTP } \\
(\mathrm{hPa})\end{array}$ & $\begin{array}{c}\text { OCCP } \\
(\mathrm{hPa})\end{array}$ & $\begin{array}{c}\sigma T_{b} \\
(\mathrm{~K})\end{array}$ & MLF & Color \\
\hline 12390 & 46.8 & 154.8 & 27.9 & 30.2 & 300 & 564 & 1.5 & 5 & red \\
12390 & 47.9 & 154.3 & 77.0 & 63.6 & 315 & 487 & 1.0 & 1 & green \\
12390 & 48.4 & 154.1 & 23.3 & 17.7 & 300 & 511 & 2.0 & 5 & blue \\
12390 & 52.0 & 152.6 & 67.6 & 53.1 & 235 & 490 & 0.9 & 1 & pink \\
12394 & -46.7 & 79.9 & 36.7 & 44.8 & 285 & 699 & 1.3 & 1 & orange \\
\hline
\end{tabular}

distinct multiple layers (red), one with a broad peak extending from about $450-800 \mathrm{hPa}$ (green), and one with a sharp peak near $650 \mathrm{hPa}$ (pink). The retrieved OCCP is at a distinctly higher pressure for the profile with a cloud extinction peak near $750 \mathrm{hPa}$ (orange). Despite differences in the vertical structure of cloud extinction, the other profiles produce similar OCCPs. In the case with distinct multiple layers (red), the optical thickness of the upper cloud deck was large $(\sim 20)$ and larger than that of the lower cloud deck. This coupled with the high solar zenith angle $\left(\sim 70^{\circ}\right)$ produces a relatively small sensitivity to the lower cloud deck.

\section{Monthly mean statistics}

Now that we have established with CloudSat that our algorithms produce reasonable results, we examine monthly mean statistics on a $1^{\circ}$ latitude by $1^{\circ}$ longitude grid for two months: January and July 2007. Figures 11 and 12 show the fraction of cloudy pixels identified as containing distinct multi-layer clouds using the OMI/MODIS and MODIS-only applied at the OMI footprint. Both instrument combinations produce similar seasonal variations. As shown in Fig. 6, the OMI/MODIS approach finds more instances of multilayer clouds in the Pacific, while the MODIS-only approach yields higher fractions at most high latitudes when the solar zenith angles are high. Due to the relatively poor sampling of CloudSat within the OMI pixel, we were unable to determine which sensor combination provides more robust results.

There are several reasons why the MODIS-only algorithm produces less detections of multi-layer clouds in tropical oceanic regions. The MODIS algorithm attempts to eliminate pixels with partial cloud coverage from their sample space, including pixels that define cloud edges. In addition, pixels are also eliminated around cloud edges. Similarly, MODIS pixels affected by sunglint and those containing aerosol are also eliminated. In contrast, all OMI pixels, including those affected by glint and aerosol, are included here. OMI is less affected by sunglint as retrievals are performed in a spectral window from 346-354 nm where Rayleigh scattering suppresses but does not completely eliminate the glint. Sunglint produces cloud fractions that are too high and cloud pressures that are too low (cloud altitudes too high). Aerosol effects on OMI retrievals are quite variable. Absorbing aerosol above and inside clouds can cause OMI to produce cloud pressures and fractions that are too low (Vasilkov et al., 2008). Non-absorbing aerosol behaves much like a cloud.

Figure 12 also shows that the MODIS-only algorithm finds more multi-layer clouds over northern Africa and parts of Australia. These are likely artifacts that get amplified in our algorithm and analysis of the data. Firstly, these regions have a low overall cloud fraction. Therefore, displaying the classifications as a fraction of cloudy cases tends to exaggerate errors. When the data are plotted as a fraction of all pixels, these areas do not stand out as much. Because these detections appear to follow continental boundaries, they could be related to the land surface albedo which is also high in the visible in these regions or to the presence of dust which may be mistaken for a low-level cloud. The surface albedo is lower over these land areas in the UV, and the OMI/MODIS algorithm does not show a land/ocean contrast in these regions.

We do not attempt to recover subpixel information in our analysis. If the MODIS MLF fraction is $>0$ within an OMI pixel, we designate that pixel as containing multilayer cloud in order to provide a more clean comparison with OMI/MODIS algorithm. If there is a small fraction of false multi-layer detections by MODIS within an OMI pixel, our analysis will tend to amplify these errors. If we set the MLF fraction threshold within an OMI pixel to a larger number, we reduce the artifacts, but also decrease the overall detection of multi-layer clouds. This leads to a poorer agreement with the OMI/MODIS algorithm that appears capable of detecting relatively small amounts of multi-layer clouds within a pixel.

OMI loses sensitivity to a lower cloud deck at high solar zenith angles as shown by Vasilkov et al. (2008) owing to the large pathlength through an upper cloud deck and the atmosphere below. This is partly due to higher Rayleigh optical thickness at higher slant paths. The MODIS MLF will be less affected by this because it uses near-IR wavelengths. This may explain why OMI/MODIS detects smaller fractions of multi-layer clouds at high latitudes (high solar zenith angles). 

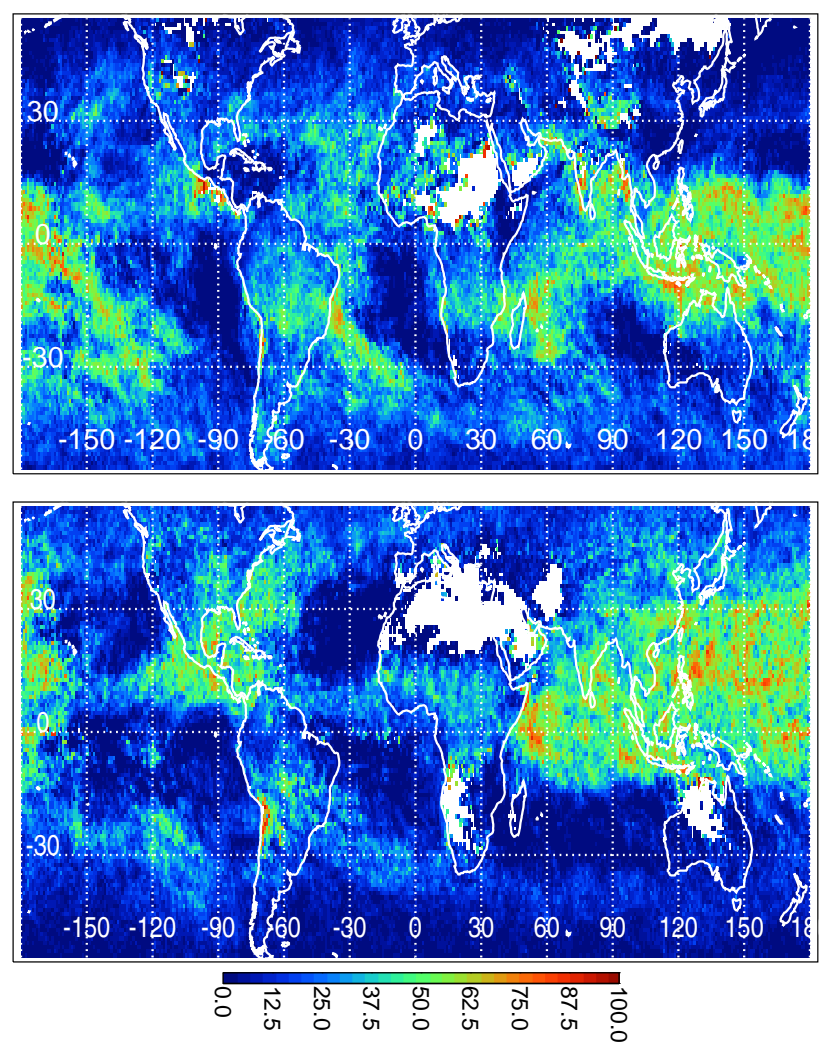

Fig. 11. Fraction of cloudy pixels designated as distinct multi-layer as derived from OMI/MODIS for January (top) and July (bottom) 2007.

Figure 13 similarly shows the fraction of cloudy pixels identified as containing vertically-extended clouds by the OMI/MODIS algorithm. Because both the OMI/MODIS and MODIS-only algorithms rely on similar logic for this identification, the MODIS-only statistics are very similar and are not shown. Seasonal variations are apparent in the intertropical convergence zone (ITCZ) and in convective areas over land.

We next examine the effect of spatial resolution on the derived cloud fractions. Figure 14 shows monthly-mean results of the MODIS-only algorithm applied at the MODIS resolution. As may be expected, at this higher spatial resolution, there are significantly smaller fractions of pixels containing multi-layer clouds. Tian and Curry (1989) obtained a similar result at larger spatial scales.

The effect of spatial resolution is further detailed in Table 4 , where it can be seen that the fraction of cloudy pixels designated as multi-layer at the MODIS resolution is only about half of that at the OMI resolution. This indicates that either the multiple cloud layers are not always coincident on the scale of the OMI footprint and/or that the multiple cloud layers are occurring at smaller spatial scales than the OMI footprint. In contrast, the percentage of pixels with vertically-extended clouds at the MODIS resolution is about
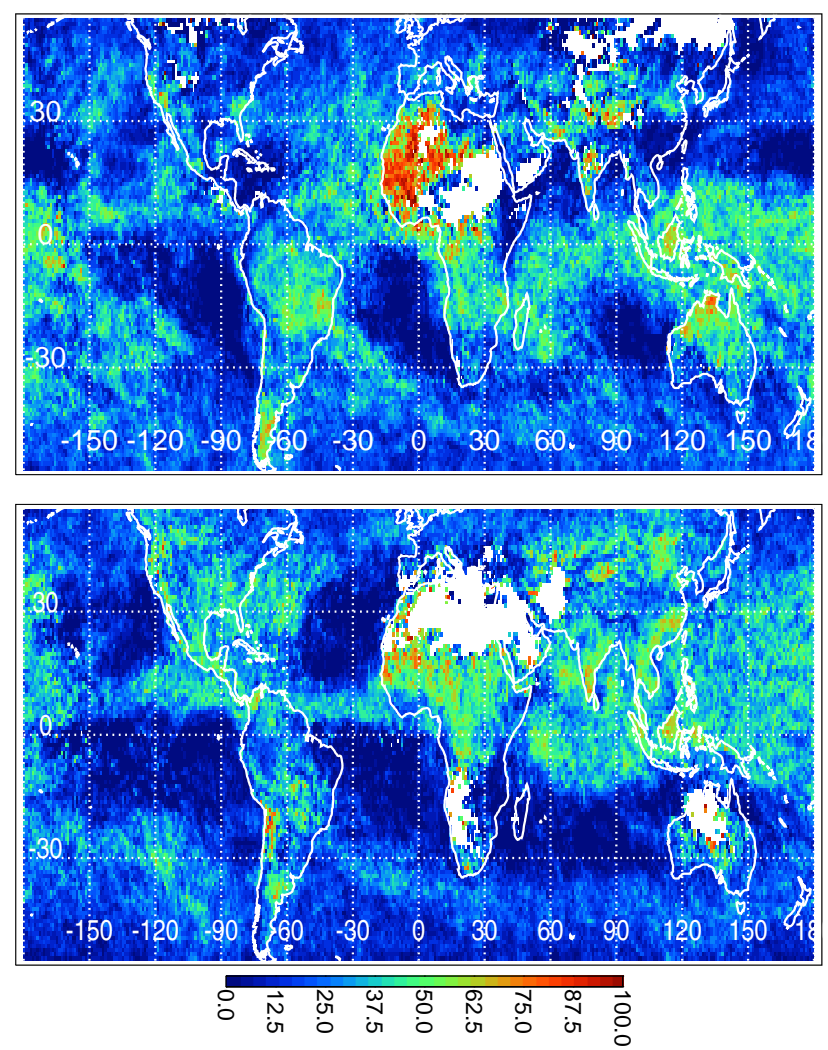

Fig. 12. Similar to Fig. 11 but results from MODIS-only on the OMI pixel.

$75 \%$ of that at the OMI resolution; The vertically-extended clouds thus appear to be filling the OMI pixels more of the time.

Table 4 also provides monthly statistics (for July 2007) separately for land and ocean. As may be expected, there are more vertically-extended clouds over land than ocean particularly in the tropics and the summer (Northern) Hemisphere. Land/ocean differences in distinct multi-layer clouds are not as apparent.

We checked the classification statistics across the OMI swath. We found lower(higher) fractions of multi(single)layer clouds at the swath edges for both the OMI/MODIS and MODIS-only algorithms as compared with the swath center. There are two competing effects that should produce acrosstrack variations in the cloud classification: (1) The spatial resolution effect shown above should produce higher fractions of pixels with multi-layer clouds at the swath edge as compared with the nadir; OMI pixels are significantly larger at the swath edges (e.g., over $100 \mathrm{~km}$ wide at the swath edge), as compared with nadir ( $24 \mathrm{~km}$ wide). (2) Reduced sensitivity at higher view angles owing to increased path lengths through clouds and atmosphere (Vasilkov et al., 2008) should result in smaller fractions of pixels with multi-layer clouds at the swath edge as compared with nadir. This reduction 

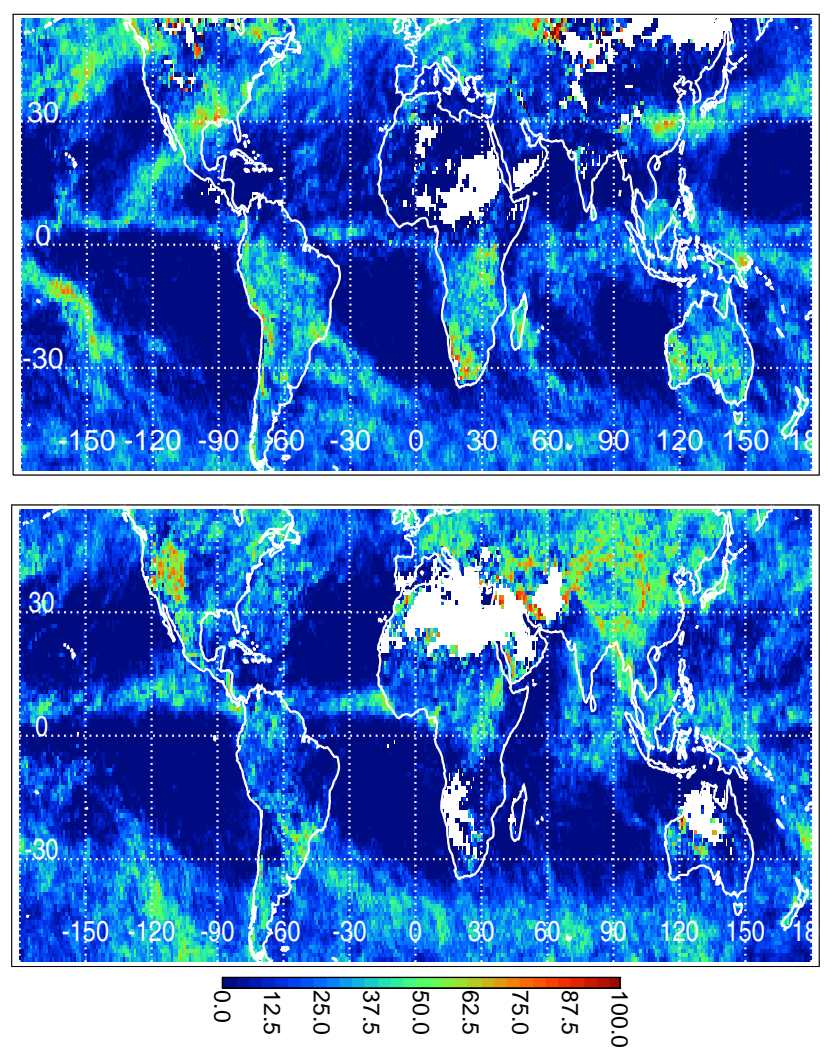

Fig. 13. Fraction of cloudy pixels designated as vertically-extended by the OMI/MODIS algorithm for January (top) and July (bottom) 2007.

in sensitivity is larger for OMI than for MODIS owing to the larger Rayleigh optical thickness at the UV wavelengths that are used in the OMI Raman cloud algorithm. Our results show lower fractions of multi-layer clouds at the swath edges. This suggests that cross-track sensitivity variations dominate over the spatial resolution effect. The cross-track variations were somewhat larger for OMI/MODIS $(\geq 15 \%)$ than for MODIS-only $(\sim 10 \%)$ which is consistent with this explanation.

\section{Conclusions}

In this work we have compared satellite cloud classification results from passive sensors with those from a coincident cloud radar for a wide range of conditions. We have shown that simple threshold algorithms based on a small number of satellite-derived quantities have skill in distinguishing between distinct multi-layer and vertically-extended clouds. The algorithm thresholds work well globally, leading to an approach that is straight-forward to implement once the initial retrievals and collocation steps are completed. In the near future, we plan to provide data sets containing MODIS statistical data on the OMI footprint as well as the output of our
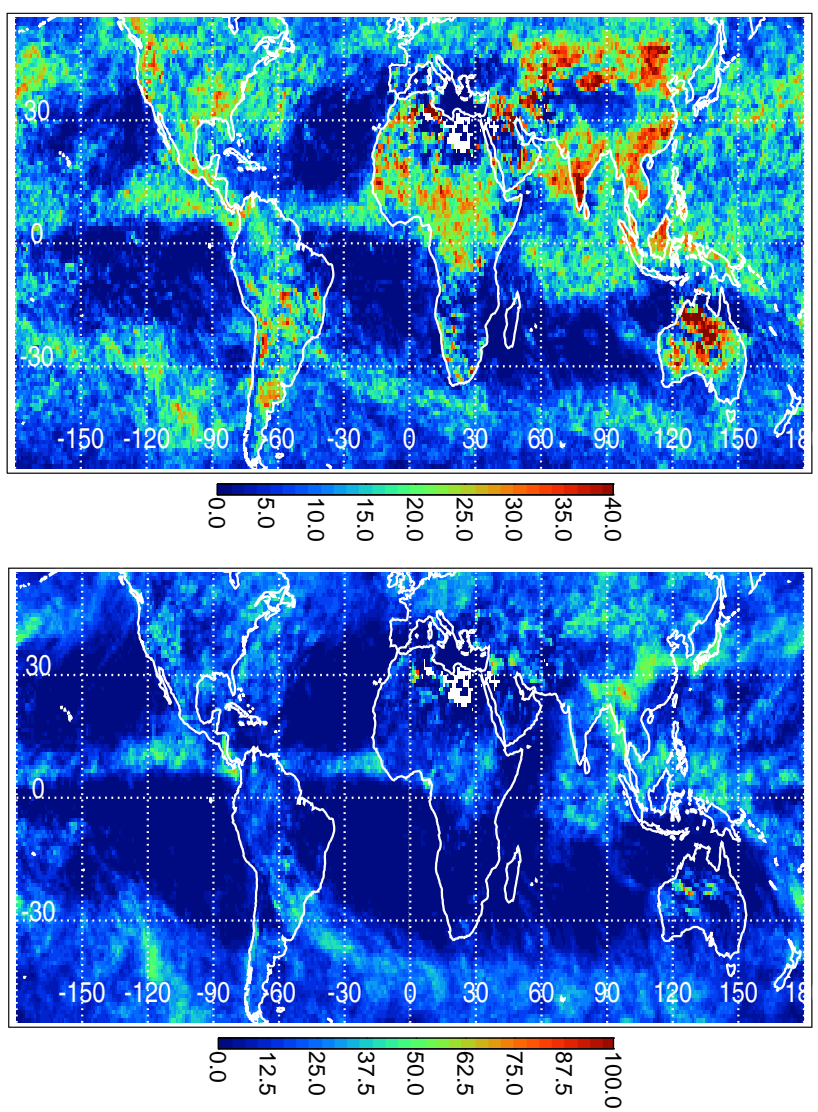

Fig. 14. Results for MODIS-only, July 2007 derived from the $(5 \mathrm{~km})^{2}$ data: Fraction of cloudy pixels designated as multi-layer (upper, note that the scale is different from all similar panels) and vertically-extended (lower).

multi-layer detection as part of our standard OMI cloud data processing. This is a first step towards achieving reliable estimates of cloud properties in multi-layer clouds using passive IR and UV/VIS sensors.

Our results have implications for calculations of cloud radiative forcing. The dependence of short-wave cloud forcing on the assumed optical centroid cloud pressure is relatively large. For typical tropical mid-latitude conditions, the difference in cloud forcing for a high and low cloud can be of the order of tens of $\mathrm{W} / \mathrm{m}^{2}$, largely due to water vapor absorption. It is therefore important to identify multi-layer clouds and use a cloud pressure appropriate for short-wave calculations. Vertically-extended clouds should also be identified and treated appropriately; The optical centroid cloud pressure is more appropriate than the cloud top for short-wave calculations under these conditions.

The relatively large fraction of OMI pixels that contain multiple cloud layers $(\sim 20 \%)$ implies that the interpretation of trace-gas retrievals in cloudy conditions must be undertaken with care, especially for gases that are not well mixed. The generation of cloud climatologies and trends 
Table 4. Monthly-mean cloud classification statistics using passive sensors for July 2007 (given as \% of cloudy pixels designated as either single cloud layer, distinct multiple layers, or vertically-extended) using the different passive sensor configurations- OMI/MODIS on the OMI footprint (left 3 columns), MODIS-only on the OMI footprint (middle 3 columns), or MODIS-only at $5 \mathrm{~km} \times 5 \mathrm{~km}$ resolution (right 3 columns).

\begin{tabular}{|c|c|c|c|c|c|c|c|c|c|}
\hline \multirow[b]{2}{*}{$\begin{array}{l}\text { Latitudes, } \\
\text { conditions }\end{array}$} & \multicolumn{3}{|c|}{$\begin{array}{l}\text { OMI+MODIS } \\
\text { OMI resolution }\end{array}$} & \multicolumn{3}{|c|}{$\begin{array}{l}\text { MODIS-only } \\
\text { OMI resolution }\end{array}$} & \multicolumn{3}{|c|}{$\begin{array}{l}\text { MODIS-only } \\
\text { MODIS resolution }\end{array}$} \\
\hline & $\begin{array}{l}\text { Sing. } \\
\text { layer }\end{array}$ & $\begin{array}{l}\text { Multi- } \\
\text { layer }\end{array}$ & $\begin{array}{l}\text { Vert. } \\
\text { Ext. }\end{array}$ & $\begin{array}{l}\text { Sing. } \\
\text { layer }\end{array}$ & $\begin{array}{l}\text { Multi- } \\
\text { layer }\end{array}$ & $\begin{array}{l}\text { Vert. } \\
\text { Ext. }\end{array}$ & $\begin{array}{l}\text { Sing. } \\
\text { layer }\end{array}$ & $\begin{array}{l}\text { Multi- } \\
\text { layer }\end{array}$ & $\begin{array}{l}\text { Vert. } \\
\text { Ext. }\end{array}$ \\
\hline $90^{\circ} \mathrm{S}-90^{\circ} \mathrm{N}$, all & 58.7 & 21.0 & 20.3 & 56.1 & 22.7 & 21.2 & 74.3 & 9.6 & 16.1 \\
\hline $90^{\circ} \mathrm{S}-90^{\circ} \mathrm{N}$, land & 48.5 & 22.6 & 28.9 & 40.6 & 28.9 & 30.4 & 67.9 & 11.4 & 20.7 \\
\hline $90^{\circ} \mathrm{S}-90^{\circ} \mathrm{N}$, oc. & 62.1 & 20.4 & 17.5 & 61.3 & 20.7 & 18.1 & 76.5 & 8.9 & 14.6 \\
\hline $20^{\circ} \mathrm{S}-20^{\circ} \mathrm{N}$, all & 54.1 & 30.1 & 15.8 & 56.4 & 27.5 & 16.2 & 76.3 & 10.1 & 13.5 \\
\hline $20^{\circ} \mathrm{S}-20^{\circ} \mathrm{N}$, land & 49.6 & 28.9 & 21.5 & 42.3 & 35.5 & 22.3 & 71.8 & 12.5 & 15.7 \\
\hline $20^{\circ} \mathrm{S}-20^{\circ} \mathrm{N}$, oc. & 55.5 & 30.4 & 14.1 & 60.6 & 25.1 & 14.4 & 77.7 & 9.4 & 12.9 \\
\hline $20^{\circ} \mathrm{N}-60^{\circ} \mathrm{N}$, all & 51.0 & 24.4 & 24.7 & 48.4 & 24.8 & 26.8 & 69.3 & 11.1 & 19.6 \\
\hline $20^{\circ} \mathrm{N}-60^{\circ} \mathrm{N}$, land & 41.3 & 24.1 & 34.5 & 33.7 & 29.2 & 37.1 & 62.3 & 12.3 & 25.3 \\
\hline $20^{\circ} \mathrm{N}-60^{\circ} \mathrm{N}$, oc. & 57.4 & 24.5 & 18.0 & 58.4 & 21.8 & 19.8 & 73.7 & 10.3 & 16.0 \\
\hline $60^{\circ} \mathrm{S}-20^{\circ} \mathrm{S}$, all & 69.4 & 10.4 & 20.2 & 62.3 & 17.2 & 20.5 & 76.4 & 7.9 & 15.6 \\
\hline $60^{\circ} \mathrm{S}-20^{\circ} \mathrm{S}$, land & 61.1 & 14.3 & 24.6 & 47.2 & 27.0 & 25.9 & 71.7 & 10.9 & 17.4 \\
\hline $60^{\circ} \mathrm{S}-20^{\circ} \mathrm{S}$, oc. & 69.8 & 10.2 & 20.0 & 63.0 & 16.7 & 20.2 & 76.7 & 7.8 & 15.5 \\
\hline
\end{tabular}

from OMI and similar instruments must also be produced and interpreted with caution. The fraction of pixels containing multi-layer clouds will be even larger for lower spatial resolution satellite UV, VIS, or near-IR instruments including GOME, GOME2, SCIAMACHY, the Total Ozone Mapping Spectrometer (TOMS), and the Ozone Mapping and Profiler Suite (OMPS) that will fly on NPOESS and NPP. Our results should be considered in trade-off studies (e.g., determining an appropriate pixel size) for future satellite missions such as UV/VIS/near-IR spectrometers that are being planned for geostationary platforms.

\section{Appendix A}

\section{Pixel filtering scheme}

Our filtering scheme uses the following checks to filter out unrepresentative pixels:

1. $\left|P_{\text {top, MODIS }}-P_{\text {top, }, \mathrm{CS}}\right|>150 \mathrm{hPa}$. This eliminates situations where CloudSat does not see a high cloud that is present within an OMI pixel (as determined by MODIS) or where CloudSat sees a very high thin cloud that is not detected by MODIS. This check may eliminate cases where the MODIS cloud top pressure is in error.

2. $\mathrm{OCCP}-P_{\text {base, } \mathrm{CS}}>100 \mathrm{hPa}$ and the CloudSat type is not vertically-extended. This filters out cases where CloudSat does not see a lower cloud deck and the OMI OCCP indicates that one is present. This check may eliminate cases where the OCCP is in error. This check is only performed for the OMI-MODIS statistics; it is not included in the MODIS-only statistics as the OMI OCCP is not available at the MODIS spatial resolution.

3. MODIS window channel brightness temperature standard deviation on the OMI pixel, $\sigma T_{b},>5 \mathrm{~K}$ and the CloudSat type is not multi-layer.

The latter two checks are only applicable to the OMI-MODIS and MODIS on OMI footprint statistics. All thresholds were determined empirically.

In order to identify subtle unrepresentative CloudSat pixels, we examined the variability of MODIS-derived quantities within the OMI pixel. The use of the MODIS cloud optical thickness standard deviation eliminated too many situations where CloudSat appeared to be representative. This occurs frequently at high optical depths. Using the MODIS cloud top pressure standard deviation within an OMI pixel likewise did not produce good results. This is because lower level cloud decks are frequently masked by an upper deck. We found that the $\sigma T_{b}$ was the most useful quantity. However, checks with this quantity miss some of the more obvious unrepresentative pixels as $T_{b}$ saturates beyond a visible optical depth of about 4 . A check on $\sigma T_{b}$ with a strict threshold also eliminates many pixels that appear to be reasonably representative.

We found that the most effective schemes for filtering out unrepresentative CloudSat pixels rely on $P_{\text {top, MODIS }}$ and OCCP. Unfortunately, these checks may eliminate pixels with erroneous $P_{\text {top, MODIS }}$ or OMI OCCP. This would tend to overestimate the agreement between the passive data and 
CloudSat. Although there has been a significant amount of validation of both $P_{\text {top, MODIS }}$ and OMI OCCP, there are known problems in both quantities. Improvements in $P_{\text {top, MODIS }}$ are planned for collection 6 to eliminate some of the problems. Likewise, improvements are also planned for future releases of the OMI Raman OCCP (e.g., an improved treatment of surface and cloud reflectance).

Acknowledgements. The material in this paper is based upon work supported by the National Aeronautics and Space Administration (NASA) under agreement NNG06HX18C issued through the Science Mission Directorate for the EOS Aura Science Team. The authors are grateful to the MODIS, OMI, and CloudSat data processing teams for providing data sets. The authors thank two anonymous reviewers for comments that helped to improve the paper. The lead author thanks A. da Silva for helpful discussions.

Edited by: B. Mayer

\section{References}

Ahmad, Z., Bhartia, P. K., and Krotkov, N.: Spectral properties of backscattered UV radiation in cloudy atmospheres, J. Geophys. Res., 109, D01201, doi:10.1029/2003JD003395, 2004.

Baum, B. A., Uttal, T., Poellot, M., Ackerman, T. P., Alvarez, J. M., Intrieri, J., Starr, D. O. C., Titlow, J., Tovinkere, V., and Clothiaux, E.: Satellite remote sensing of multiple cloud layers, J. Atmos. Sci., 52, 4210-4230, 1995.

Baum, B. A. and Spinhirne, J. D.: Remote sensing of cloud properties using MODIS airborne simulator imagery during SUCCESS 3. Cloud overlap, J. Geophys. Res., 105, 11793-11804, 2000.

Baum, B. A. and Wielicki, B. A.: Cirrus cloud retrieval using infrared sounding data: Multilevel cloud errors, J. Appl. Meteorol., 33, 107-117, 1994.

de Beek R., Vountas, M., Rozanov, V. V., Richter, A., and Burrows, J. P.: The ring effect in the cloudy atmosphere, Geophys. Res. Lett., 28, 721-724, 2001.

Chang F.-L. and Li, Z.: A new method for detection of cirrus overlapping water clouds and determination of their optical properties, J. Atmos. Sci., 62, 3993-4009, 2005.

Chang F.-L. and Li, Z.: A near-global climatology of single-layer and overlapped clouds and their optical properties retrieved from Terra/MODIS data using a new algorithm, J. Climate, 18, 45724771, 2005.

Chen T., Zhang, Y., and Rossow, W. B.: Sensitivity of atmospheric radiative heating rate profiles to variations of cloud layer overlap, J. Climate, 13, 2941-2959, 2000.

Daniel, J. S., Solomon, S., Miller, H. L., Langford, A. O., Portmann, R. W., and Eubank, C. S.: Retrieving cloud information from passive measurements of solar radiation absorbed by molecular oxygen and $\mathrm{O}_{2}-\mathrm{O}_{2}$, J. Geophys. Res., 108, 4515, doi:10.1029/2002JD002994, 2003.

González, A., Wendling, P., Mayer, B., Gayet, J.-F., and Rother, T.: Remote sensing of cirrus cloud properties in the presence of lower clouds: An ATSR-2 case study during the Interhemispheric Differences in Cirrus Properties From Anthropogenic Emissions (INCA) experiment, J. Geophys. Res., 107, 4693, doi:10.1029/2002JD002535, 2002.
Gupta, S. K., Darnell, W. L., and Wilber, A. C.: A parameterization for longwave surface radiation from satellite data: Recent improvements, J. Appl. Meteorol., 31, 1361-1367, 1992.

Heidinger, A. K. and Pavolonis. M. J.: Global daytime distribution of overlapping cirrus cloud from NOAA's Advanced Very High Resolution Radiometer, J. Climate, 18, 4772-4784, 2005.

Ho, S., Lin, B., Minnis, P., and Fan, T.-F.: Estimates of cloud vertical structure and water amount over tropical oceans using VIRS and TMI data, J. Geophys. Res., 108, 4419, doi:10.1029/2002JD003298, 2003.

Huang, J., Minnis, P., Lin, B., Yi, Y., Khaiyer, K., Arduini, R. F., Fan, A., and Mace, G. G.: Advanced retrievals of multilayered cloud properties using multispectral measurements, J. Geophys. Res., 110, D15S18, doi:10.1029/2004JD005101, 2005.

Huang, J., Minnis, P., Lin, B., Yi, Y., Fan, T. F., SunMack, S., and Ayers, J. K.: Determination of ice water path in ice-over-water cloud systems using combined MODIS and AMSR-E measurements, Geophys. Res. Lett., 33, L21801, doi:10.1029/2006GL027038, 2006.

Jin, Y. and Rossow, W. B.: Detection of cirrus overlapping lowlevel clouds, J. Geophys. Res., 102, 1727-1737, 1997.

Joiner J., Bhartia, P. K., Cebula, R. P., Hilsenrath, E., McPeters, R. D., and Park, H.-W.: Rotational-Raman scattering (Ring effect) in satellite backscatter ultraviolet measurements, Appl. Optics, 34, 4513-4525, 1995.

Joiner, J., Vasilkov, A. P., Flittner, D. E., Gleason, J. F., and Bhartia, P. K.: Retrieval of cloud pressure and oceanic chlorophyll content using Raman scattering in GOME ultraviolet spectra, J. Geophys. Res., 109, D01109, doi:10.1029/2003JD003698, 2004.

Joiner, J. and Vasilkov, A. P.: First results from the OMI rotationalRaman scattering cloud pressure algorithm, IEEE T. Geosci. Remote, 44, 1272-1282, 2006.

Joiner, J., Schoeberl, M. R., Vasilkov, A. P., Oreopoulos, L., Platnick, S., Livesey, N. J., and Levelt, P. F.: Accurate satellitederived estimates of the tropospheric ozone impact on the global radiation budget, Atmos. Chem. Phys., 9, 4447-4465, 2009, http://www.atmos-chem-phys.net/9/4447/2009/.

Koelemeijer, R. B. A. and Stammes, P.: Effects of clouds on ozone column retrieval from GOME UC measurements. J. Geophys. Res., 104, 8281-8294, 1999.

Koelemeijer, R. B. A., Stammes, P., Hovenier J. W., and de Haan, J. F.: A fast method for retrieval of cloud parameters using oxygen A band measurements from the Global Ozone Monitoring Experiment, J. Geophys. Res., 106, 3475-3490, 2001.

Kokhanovsky, A. A. and Rozanov, V. V.: Cloud bottom altitude determination from a satellite, IEEE Geosci. Remote S., 2, 280283, 2005.

Kokhanovsky, A. A., Mayer, B., Rozanov, V. V., Wapler, K., Burrows, J. P., and Schumann, U.: The influence of broken cloudiness on cloud top height retrievals using the nadir observations of backscattered solar radiation in the oxygen A-band, J. Quant. Spectrosc. Ra., 103, 460-477, 2007.

Levelt, P. F., van den Oord, G. H. J., Dobber, M. R., et al.: The Ozone Monitoring Instrument, IEEE T. Geosci. Remote, 44, 1093-1101, 2006.

Menzel, W. P., Frey, R., Zhang, H., Wylie, D. P., Moeller, C., Holz, R., Maddux, B., Baum, B. A., Strabala, K. I., and Gumley, L.: MODIS global cloud-top pressure and amount estimation: algorithm description and results, J. Appl. Meteorol. Clim., 
47, 1175-1198, 2008.

Min, Q., Harrison, L. C., and Clothiaux, E. E.: Joint statistics of photon path length and cloud optical depth: Case studies, J. Geophys. Res., 106, 7375-7385, 2001.

Minnis, P., Huang, J., Lin, B., Yi, Y., Arduini, R. F., Fan, T.F., Ayers, J. K., and Mace, G. G.: Icecloud properties in ice-over-water cloud systems using TropicalRainfall Measuring Mission (TRMM) visible and infrared scanner and TRMM Microwave Imager data, J. Geophys. Res., 112, D06206, doi:10.1029/2006JD007626, 2007.

Nasiri, S. L. and Baum, B. A.: Daytime multilayered cloud detection using multispectral imager data, J. Atmos. Ocean. Tech., 21, 1145-1155, 2004.

Platnick, S., King, M. D., Ackerman, S. A., Menzel, W. P., Baum, B. A., Riédi, J. C. and Frey, R. A.: The MODIS cloud products: algorithms and examples from Terra, IEEE T. Geosci. Remote, 41, 459-473, 2003.

Pavolonis, M. J. and Heidinger, A. K.: Daytime cloud overlap detection from AVHRR and VIIRS, J. Appl. Meteorol., 43, 762-778, 2004.

Rossow, W. B. and Schiffer, R. A.: ISCCP cloud data products, B. Am. Meteorol. Soc., 72, 2-20, 1991.

Rozanov, V. V. and Kokhanovsky, A. A.: Semianalytical cloud retrieval algorithm as applied to the cloud top altitude and the cloud geometrical thickness determination from top-of-atmosphere reflectance measurements in the oxygen A band, J. Geophys. Res., 109, D05202, doi:10.1029/2003JD004104, 2004.

Rozanov, V. V., Kokhanovsky, A. A., and Burrows, J. P: The determination of cloud altitudes using GOME reflectance spectra: Multilayered cloud systems, IEEET. Geosci. Remote, 42, 1009 1017, 2004.

Sheu, R.-S., Curry, J. A., and Liu, G.: Vertical stratification of tropical cloud properties as determined from satellite, J. Geophys. Res., 102, 4231-4245, 1997.

Sneep, M., De Haan, J., Stammes, P., Wang, P., Vanbauce, C., Joiner, J., Vasilkov, A. P., and Levelt, P. F.: Three way comparison between OMI/Aura and POLDER/PARASOLcloud pressure products, J. Geophys. Res., D15S23, doi:10.1029/2007JD008694, 2008.

Spurr, R. J. D., de Haan, J., van Oss, R., and Vasilkov, A. P.: Discrete ordinate radiative transfer in a stratified medium with first order rotational Raman scattering, J. Quant. Spectrosc. Ra., 109, 404-425, 2008.

Stephens, G. L., Vane, D. G., Taneli, S., et al.: CloudSat Mission: Performance and early science after the first year of operation, J. Geophys. Res., 113, D00A18, doi:10.1029/2008JD009982, 2008.
Tian, L. and Curry, J. A.: Cloud Overlap Statistics, J. Geophys. Res., 94, 9925-9935, 1989.

Vanbauce, C., Cadet, B., andMarchand, R. T.: Comparison of POLDER apparent and corrected oxygen pressure to ARM/MMCR cloud boundary pressures, Geophys. Res. Lett., 3, 1212, doi:10.1029/2002GL016449, 2003.

Vasilkov, A. P., Joiner, J., Yang, K., and Bhartia, P. K.: Improving total column ozone retrievals by using cloud pressures derived from Raman scattering in the UV, Geophys. Res. Lett., 31, L20109, doi:10.1029/2004GL020603, 2004.

Vasilkov, A. P., Joiner, J., Spurr, R. J. D., Bhartia, P. K., Levelt, P., and Stephens, G.: Evaluation of the OMI cloud pressures derived from rotational Ramanscattering by comparisons with other satellite data and radiative transfer simulations, J. Geophys. Res., 113, D15S19, doi:10.1029/2007JD008689, 2008.

Vasilkov, A. P., Joiner, J., Oreopoulos, L., Gleason, J. F., Veefkind, P., Bucsela, E., Celarier, E. A., Spurr, R. J. D., and Platnick, S.: Impact of tropospheric nitrogen dioxide on the regional radiation budget, Atmos. Chem. Phys., 9, 6389-6400, 2009,

http://www.atmos-chem-phys.net/9/6389/2009/.

Wagner, T., Beirle, S., and Deutschmann, T.: Three-dimensional simulation of the Ring effect in observations of scattered sun light using Monte Carlo radiative transfer models, Atmos. Meas. Tech., 2, 113-124, 2009, http://www.atmos-meas-tech.net/2/113/2009/.

Wang, J. and Rossow, W. B.: Effects of cloud vertical structure on atmospheric circulation in the GISS GCM, J. Climate, 11, 30413056, 1998.

Wielicki, B. A., Cess, R. D., King, M. D., Randall, D. A., and Harrison, E. F.: Mission to Planet Earth: Role of clouds and radiation in climate, B. Am. Meteorol. Soc., 76, 2125-2153, 1995.

Wind, G., Platnick, S., King, M. D., Hubanks, P. A., Baum, B. A., Pavolonis, M. J., Heidinger, A. K., Yang, P., and Kratz, D. P.: Multilayer cloud detection with MODIS near-infrared water vapor absorption band, J. Appl. Meteorol. Clim., submitted, 2010.

Winker, D. M., Hunt, W. H., and McGill, M. J.: Initial performance assessment of CALIOP, Geophys. Res. Lett., 34, L19803, doi:10.1029/2007GL030135, 2007.

Ziemke, J. R., Joiner, J., Chandra, S., Bhartia, P. K., Vasilkov, A., Haffner, D. P., Yang, K., Schoeberl, M. R., Froidevaux, L., and Levelt, P. F.: Ozone mixing ratios inside tropical deep convective clouds from OMI satellite measurements, Atmos. Chem. Phys., 9, 573-583, 2009, http://www.atmos-chem-phys.net/9/573/2009/. 